\title{
Effect of a Medium Fidelity Simulation Based Training on Nurses' Knowledge, Performance and Clinical Judgment of Postpartum Hemorrhage Management
}

\author{
Nevertity Hassan Zaky \\ Assistant Professor, Obstetrics, and Gynecology Nursing Department, Faculty of Nursing, of Alexandria \\ University, Egypt
}

\begin{abstract}
Simulation training is a valuable method to improve maternity nurses knowledge, performance skills and clinical judgment to saving the women health outcome who are deteriorating from postpartum hemorrhage. Therefore, this study aimed to evaluate the effect of a medium fidelity simulation based training on nurses' knowledge, performance and clinical judgment of postpartum hemorrhage management. Research Design: It was an quasi-experimental study The setting the study was conducted at two of Alexandria University Hospitals: Elshatby Maternity hospitals, and Borg El Arab hospital, The sample comprised a conveniently chosen 100 maternity nurses working in the previously mentioned setting, they were randomly assigned equally into either a study or a control group. The tools, three tools were validated and used to collect data; Tool I: Maternity nurses' knowledge about primary postpartum hemorrhage Questionnaire Tool II: Maternity nurses' performance skills for the management of primary postpartum hemorrhage observational checklist: Tool III clinical judgment rubric (LCJR) checklist observation sheet. The results accordingly proved that the majority of nurses had fair and poor knowledge and unsatisfactory performance skills and low mean score of clinical judgment about management of PPH before simulation training with no statistically significant difference between the study and control groups. Yet, after one and three months from the simulation training the nurses' knowledge, performance and clinical judgment were significantly improved among the study group than control one. It can be concluded that simulation training for maternity nurses had a positive effects in improving nurses knowledge, performance skills and, capture the skills to construct effective clinical judgment. Consequently, it was recommended to conduct ongoing in service simulation training program based on evidence-based practices for maternity nurses about obstetric emergency situation.
\end{abstract}

Keywords: A medium fidelity simulation, nurses' knowledge, performance skills, clinical judgment, postpartum hemorrhage.

\section{Introduction}

Postpartum hemorrhage ( $\mathrm{PPH})$ is a common and potentially life-threatening obstetric emergency associated with both the vaginal birth and cesarean section. Indeed PPH is the leading causes of maternal morbidity and mortality in worldwide. Globally, 35\% of maternal deaths are associated with PPH. Foremost maternal mortality declined substantially in Egypt during 1995-2008, from 230 to 66 deaths per 100,000 live births. In this context, the maternal mortality ratio stood at 45 deaths per 100,000 live births in 2013 according to the World Health Organization (WHO). (1-4). Although this ratio is not uppermost by standards for developing countries, where the average is 230 , it is still significantly above the average of 16 in developed countries. Of the three types of hemorrhage antepartum, intrapartum and postpartum, the postpartum type is definitely the most important, accounting for $73 \%$ of all hemorrhage cases. It is a life menacing event that can occur with little warning and is often unrecognized until the mother has profound symptoms ${ }^{(1-3)}$

World Health Organization (WHO) defines PPH as $500 \mathrm{ml}$ of blood loss after vaginal birth and 1000 $\mathrm{ml}$ of blood loss in case of cesarean births3from the genital tract after delivery, or blood loss sufficient to cause signs or symptoms of hemodynamic compromise. The bleeding that occurs during the first 24 hours after delivery is called primary hemorrhage, which is responsible for $80 \%$ of PPH. Uterine atony is the main cause of primary PPH, followed by retained placental tissue, genital tract trauma lacerations uterine rupture or maternal coagulation disorders. In contrast, secondary PPH occurs after 24 hours of birth until six weeks. Actually, PPH is a significant contributor to severe maternal morbidity and long-term disability associated with more substantial blood loss, including s ruptured uterus, severe hemorrhage, shock, septicemia, organ failure, venous and coagulopathy conditions. By early detection and management, in a timely manner can be lifesaving. In the spectrum of obstetrical emergencies, massive obstetrical hemorrhage is of the most concern provoking situations encountered by obstetrical care providers. Effective management has evolved to include a variety of medical and nursing strategies which shown to improve outcomes ${ }^{(4,6)}$. 
The prevention and treatment of PPH considered as the vital steps towards improving the health of women during childbirth and the achievement of the Millennium Development Goals. Therefore maternity nurses and obstetricians need to be engaged in ongoing simulation training in developing and maintaining update knowledge, vigilant clinical competencies skills, and proper accurate clinical judgments based on universal guideline protocol for the early detection and pivotal nursing management in a timely manner. Consequently, maternity nurses can save the life of women who are clinically deteriorating from postpartum hemorrhage. . $^{-10)}$

Simulation "one of the most important resources in nursing education today" is an active teaching technique in healthcare education as it mimics real-life experiences that evoke substantial aspects of the real world in a fully interactive fashion. ".Technology has evolved to the point where simulation include very sophisticated, life-like computer-driven manikins, often referred to as high-fidelity simulators that blink, breathe, talk, and bleed. Further type of simulation named Patient-focused simulation (PFS) is a hybrid simulation method where part task trainers, mannequins of any fidelity and various training equipment are combined with a simulated patient (Sip) allows for more scope, in that a person is asked to act as a patient, portraying specific behavioral and physical symptoms in order to meet various, specific, simulation learning objectives integrating a patient-actor with a mannequin, is effective and inexpensive. The use of a patient actor can increase the realism of the situation and improve communication between healthcare professionals and patients. Hybrid simulation balances the essential art of caring with skill acquisition to cultivate technologically informed person-centered care. ${ }^{(11-13)}$

Simulation is a valuable tool for nurses to experience of a variety of clinical situations in a safe environment. When nurses are immerse themselves in the simulation scenario they are more engaged, experience a deeper learning and have unique opportunities to be able to apply the acquired knowledge into the clinical practice, develop technical clinical skills, a holistic behaviors approach, and, increased awareness of patient needs and more empowered to advocate for their patients. Moreover improving teamwork competencies and communication to analyze situations, and make accurate clinical judgment for solving the clinical problems. Clinical judgment is an essential skill in caring for patients, to improve the quality of nursing care. However wholly unanticipated that essential knowledge and satisfactory practical skills cannot guarantee to solve the patient problem and providing high-quality nursing service. Ultimately the essence of effective nursing care besides knowledge and performance skills is reliable, accurate timely manner clinical judgments. Substantially the use of simulated situations allows nurses to apply theoretical knowledge to analyze clinical situations systematically, reason situations analytically and develop clinical judgment through the integration of critical thinking and clinical reasoning, with problem-solving approach, likewise prioritizing and time management which reflects proper judgments, needed for safe and effective woman care, by using proper designed scenarios. And thus, nurses are being more cognizant to render efficient, effective nursing care with the aim of improving women health outcome. As Such nurses develop deeper understanding of the clinical situation which allow them to progress from reliance on abstract knowledge, static nursing care to deep analysis and interpretation, reasoning and response with reliable sound clinical judgments. ${ }^{(14,15)}$

\section{Significance of the study}

Because of the significant morbidity and mortality associated with PPH. Maternity nurses are the frontline health care providers multifaceted with responsibilities to improve women health, decrease morbidity and saving the mother's life this can be achieved through improving knowledge, technical skills, besides Clinical decision making and judgment. Therefore, it is vital to participate maternity nurses in ongoing standardized simulation training based on evidence-based nursing practices for fidelity simulation provides a realistic setting that promotes a different approach to transferring knowledge into practice. This approach prove for preparing nurses to respond competently in emergency situations through prevention and prompt management of $\mathrm{PPH}^{\cdot(3,8,10)}$.

\section{Aim of the Study}

To assess the effect of a medium fidelity simulation based training program on maternity nurses' knowledge, performance skills and clinical judgment of primary postpartum hemorrhage management.

\section{Research Hypotheses}

- Maternity nurses who attend simulation-based training program exhibit higher knowledge, performance skills, clinical judgment score than those who did not attend it.

\section{Operation definition:}

Nursing performance skills here refers to their role in prevention and management of atonic PPH 
Design:

\section{Materials and method}

Quasi-experimental study research design was used.

\section{Materials}

Settings:

The study was carried out at the clinical lab of El Shatby Maternity University hospital and Borg El Arab hospital. By using middle fidelity simulator (hybrid simulation)

\section{Subjects:}

The study comprised a purposive sample of maternity nurses who are working in Emergency, Intensive Care, postpartum, and abortion, units in the above-mentioned settings (100 Maternity nurses)

Tools:

Three tools were used for data collection.

Tool I: Maternity nurses' knowledge about primary postpartum hemorrhage Questionnaire.

It includes two parts Part I: Maternity nurses' professional profile was developed and used by the researcher to collect data about age, level of education, position and years of experience, training program attendance.

Part II: Maternity nurses' knowledge about primary postpartum hemorrhage Questionnaire: It was developed by the researcher. It comprised 54 multiple choice questions in 4 main groups as follows: 1- General knowledge (10 items),2- Active managements of the third stage of labor (7 items).3- general nursing management of postpartum hemorrhage, (20 items). 4-Nurses role of managing a tonic PPH.(17 items).Maternity nurses' response vary to each item between incorrect answer (1), correct but not complete (2), correct and complete (3). The total score was ranged between $36-162$. The total knowledge score was summed up and categorized as follows; Poor for total score 36- <90, Fair for total score 90 - >126, Good for total score $126-162$

Tool II: Maternity nurses' performance skills observational checklist: This tool was adapted from The WHO 2012"guidelines for Managing Complications in Pregnancy and Childbirth: A guide for midwives and doctors". ${ }^{(10) .}$ It was included 82 items in two main groups: first, active management of the third stage of labor (12 items). Second part Maternity nurses' performance skills in managing atonic $\mathrm{PPH}(70$ items $)$ which encompass call for help(4 items),resuscitation(12 items), assessment\& estimated amount of blood (7 items), basic nursing measures(12 items), arrest the bleeding( External Bimanual uterine massage (rubbing up to the funds, internal bimanual uterine compression abdominal aortic, compression. Apply Non - pneumatic anti-shock garment (NASG) (18 items) monitoring\& investigation (8items), evaluation \&documentation (9 items) Maternity nurses' skills were scored as follows: competently Performed (3), incompetently Performed (2) not done (1).The total score was ranged between 82-246. The level of nurses 'performance skills was classified as unsatisfactory skills for a total score $<209$ - satisfactory skills $>209-246$.

Tool III: lasater clinical judgment rubric (LCJR) checklist observation sheet.it was adapted from Tanner's clinical judgment model, Lasater (2007) ${ }^{(15)}$ uses Likert scale scoring to measure the 4 corresponding dimensions. 1-noticing, (3 dimensions) 2-interpreting, (2 dimensions) 3- Responding, (4 dimensions). 4Effective reflecting ( 2 dimensions). Clinical judgment item was scored as follows $1=$ beginning, $2=$ developing, 3 = accomplished, and or 4 = exemplary. The total score on the LCJR can range from 11 to 44 . A higher score indicates better performance in clinical judgment.

\section{Methods;}

The study was executed according to the following steps:

Approval was obtained from the Ethical Committee of the faculty of nursing- Alexandria University and then from responsible authorities of the study setting.

\section{Tool development}

Tool I was developed by the researcher after the extensive review of the relevant and recent literature. While tool II was adopted from WHO 2012 \&tool III was adopted from Tanner's (2006). The tools were later validated by 5 experts in the related fields. The reliability of tool I\& III was accomplished by split-half reliability technique. The scale has high internal consistency with Cronbach's alpha tool II $=0.92$, and tool III= 0.815 .

\section{Pilot study}

A pilot study was carried out on 5 maternity nurses, who were excluded from the study subjects to ascertain the relevance feasibility, clarity of tools, as well as detect any problem peculiar to the statements 
subsequently, the tools were corrected accordingly and made ready for use. Data collection covered a period of six months, from the beginning of April to the end of September 2016.

Ethical considerations: For each recruited subject, securing the informed consent, keeping privacy, assuring of data confidentiality and the right to withdraw at any time was considered.

\section{Statistical Analysis}

Statistical analysis was performed using SPSS version 20 for Windows. Frequency and percentage were used for describing and summarizing categorical data. $\mathrm{MH}$ : Marginal Homogeneity test and McNamara test *significant at $\mathrm{P} \leq 0.05$. $\mathrm{P}$ : to compare the study and control group nurses level of knowledge, performance skills and clinical judgment before and after one, three months from simulation training program implementation. Frequency \& Pearson coefficient was conducted to find a correlation between clinical judgment scores with knowledge and performance skills score. The significance of the results was judged at the 5\% level.

\section{Program development phase: 1-Pre-assessment phase:}

A written consent was obtained after explaining purpose of the study to all participants The pretest to assess maternity nurses' knowledge using tool 1 by a self-report on an individual basis while the performance skill and clinical nursing judgment were observed by the researcher when the participants demonstrating the procedures using middle fidelity simulation (objective structured clinical exam (OSCE) station using tool 11 \& 111. Depending on the results, a medium fidelity simulation based program was developed and revised by 3 experts in the related field.

\section{1-program aim}

To improve maternity nurses 'knowledge, performance skills and Clinical judgment skills in daily nursing care for the management of primary postpartum hemorrhage.

\section{2- Content}

It was selected based on the program objectives \& maternity nurses' assessment needs. Study group received both theoretical part and simulation training about nursing management of primary PPH. The simulations use the middle-technology hybrid birth, which are worn by a patient actress to simulate the obstetric emergency scenarios. It constitutes a vaginal opening with uterus to deliver placenta, and pocket for an IV bag with tubing for simulated blood loss. In contrast, after the entire study was finished the control group received the same content of the simulation training program to avoid biasing about nursing management of primary $\mathrm{PPH}$.

\section{3-Implementation phase}

The study group participants' were further assigned randomly into ten subgroups; which included 5 nurses for the purpose of training. The program was implemented in 10 weeks, each subgroup cover one week. Three sessions in three consecutive days were scheduled (6hours each session). The training course for each subgroup includes 6hour theoretical with a 12-hour clinical experience at simulated clinical environment. All theoretical session were followed by simulation training. The program sessions were implemented as follows:

\section{Theoretical and Training sessions:}

Session (1): included basic knowledge about primary PPH as definition, types, causes, signs \&symptoms, highrisk group, prevention during antenatal, labor, postpartum period, Complication. Followed by demonstrating nursing assessment for early detection and prevention.

Session (2): included active management of the third stage of labor (followed by simulation training with the proper scenario through demonstration \& re-demonstration of nurses' performance skills

Session (3): included nursing management of atonic postpartum followed by demonstration \&remonstration of nurses' performance skills in simulated virtual environment.

4-debriefing: Immediately, following the simulation researcher conducted debriefing as a reflective activity. This lasted about 30 minutes it includes constructive feedback, correction, clarifying, discussing the experience, learn from mistakes, and pitfall.

5-evaluation: Posttest was implemented after one and three months from simulation training program. Standardized assessments using multiple choice questions and objective structured clinical examination (OSCE) were used to measure retention of knowledge, sustained improvement in performance skills and clinical judgment using the tool (I) to assess nurses knowledge While maternity nurses' skills and clinical judgments were checked by the researcher using the tool II\& III were observed by the researcher when the nurses demonstrating the procedures using middle fidelity simulation (objective structured clinical exam (OSCE) station using tool $11 \& 111$. 


\section{Results:}

Table (1) indicates no significant differences between the study and control groups in their age, the level of education, years of experience and attending emergency obstetric training. In this regard, about half (54\%\&50\%) of both study and control groups between the ages of 30 to 40 years while, more than three-quarter of both groups $(80 \% \& 76 \%)$ respectively had a diploma in nursing. Also, more than half of both groups $(54 \% \& 60 \%) \&(62 \% \& 68 \%)$ respectively had more than 10 years' experience, and attend emergency obstetric training.

Table (2)\& Figure (1) clarifies the percent distribution of nurses' knowledge regarding primary PPH before and after one and three months from simulation training program implementation. However, the level of knowledge before program implementation was mainly fair and poor among both the study and control groups. Additionally, there was no statically significant difference between the two groups as regards all aspects of knowledge. Yet, one and three months after program implementation, there was a statically significant difference between the two groups in favor of the study group, progressive improvement in all knowledge aspect was obvious. One month since simulation training implementation, advanced improvement in all knowledge aspects were obvious among the study group (80\%), reported good knowledge while $(64 \%)$ of the control group had poor knowledge with a statistically significant difference between the two groups $(\mathrm{P}<0.0001)^{*}$. Three months later, sustained retention of knowledge among the study group was exist (78\%) had total good knowledge The opposite was noticed among the control group were $(62 \%)$ of them had poor knowledge. Accordingly, there were a high statistically significant difference between the study and control groups after one month $\left(\mathrm{P}=0.0001^{*}\right)$, and after three months $\left(\mathrm{P}=0.0001^{*}\right)$ in all knowledge aspects covered in this study in a similar way.

Table (3) \&Figure (2) reveals a percent distribution of the Study subjects according to their nursing performance skills of atonic PPH before and after the simulation training program. According to the used significant tests results, there were no statistically significant differences between the study and control groups in all aspects of the nursing care performance before the simulation training program as the majority of both groups $(84 \% \& 82 \%)$ respectively had an unsatisfactory practice. One and three months after the training program. There was a statistically significant difference $(\mathrm{P}<0.0001)$ between the study and control groups in favor of the study group. Where the majority of the study ( $88 \%$ and $82 \%$ ) compared to only (16\% and $18 \%)$ of control group respectively had satisfactory performance skills. The difference was statistically significant $\mathrm{MNP}<0.0001 *$

Table (4) portrays the total mean score of clinical judgment which entails noticing, interpreting, responding and reflecting of the study subjects before and after simulation training program implementation. However, the clinical judgments before program implementation was mainly low among both the study and control groups. Moreover, there was no statically significant difference between the two groups in all clinical judgment domains before program implementation; noticing $\mathrm{p}=(\mathrm{P}=.134)$, interpreting $\mathrm{p}=(\mathrm{P}=.473)$, responding $\mathrm{p}=(336)$, reflecting $\mathrm{p}=(\mathrm{P}=.262)$. Yet, one month after program implementation, there was a statically significant difference between the two groups in favor of the study group $\left(\mathrm{P}=.000^{*}\right)$, whereas the study group report a total mean score of $33.87 \pm 4.47$.in contrast, the control group continued to report the low level of all domain of clinical judgment with the mean score $19.45 \pm 2.42$. Moreover, one month later the study group accentuate significant progress in all domains of clinical judgment with total mean score was 33.87 \pm 4.47 compared to19.45 \pm 2.42 of the control group. Highly statistically significant differences was noted $(\mathrm{P}=.000 *)$, three months later, a considerable maintains of high clinical judgment score was obvious among the study group, with the total mean score $31.65 \pm 3.17$. On the other hands the control group exhibit regress in total mean score of clinical judgment $(18.77 \pm 2.87)$ reflecting a high, statistically significant difference between the two groups $(\mathrm{P}=.000 *)$

Table (5) elicit that there were significant negative correlations $(\mathrm{P})$ at level $(0.293 \& 0.253)$ between the clinical judgment of the study and control groups respectively with their knowledge and skills performance before simulation training program implementation. However, after one and three months the study group indicate a positive Pearson correlation coefficient $(\mathrm{P})$ at level $(<0.001)$ between clinical judgment with their knowledge and skills. This elaborates the higher knowledge and skills associated with greater improvement in clinical judgment scores. Meanwhile, the control group continue to shows negative Pearson correlation coefficient between clinical judgment with their knowledge and skills after one month $(\mathrm{P}=0.346 \& \mathrm{P}=0.153)$, and after three months $(\mathrm{P}=-0.046 \& \mathrm{P}=-0.035)$ respectively.

\section{Discussion}

Although most pregnancies and births are uneventful, approximately $15 \%$ of all pregnant women develop a potentially life-threatening complication that calls for skilled care and some will require a major obstetrical intervention to survive. However, care was hampered by insufficient teamwork, interpersonal skills, knowledge, technical performance skills critical thinking, problem-solving approaches and formulate 
appropriate professional judgment. Substantially obstetric emergencies are to some extent inevitable and training staff to manage these emergencies is a fundamental principle of risk management. Therefore all health professionals involved in caring for women should be competent in early detection to promote the effectiveness, efficiency, and safe quality nursing care with team-working when obstetric emergencies arise. Virtually experiential learning through simulation provides practicing nurses with the ability to apply theirs knowledge, skill, and problem-solving, clinical judgment abilities needed for safe and effective women care in context. ${ }^{(8,9) \text {. }}$

The results of the present study revealed that nurses of both the study and control groups were matching in almost all aspects of their professional characters. This matching is valuable in limiting extraneous variables, which could interfere with the effect of the intended simulation training program on nurses knowledge performance, skills, and clinical judgment.

The findings recognize no significant difference between the study and control group before simulation training program. Indeed around two-thirds of both groups had fair and good level of general knowledge. This results may be attributed to the fact that the participant attend periodic didactic courses of obstetrics emergency including PPH within previous five years. As expected significant improvement of knowledge level among the study group after one and three months of simulation training. This result is in agreement with Ayres C. et al,(2011). ${ }^{(16)}$ they examining knowledge gained through simulation training, participant demonstrated a significant increase and sustained of midwives knowledge following simulation training. Similarly Kumar N. et al,(2016). ${ }^{(17)}$ \& Ameh C. et al,(2012). ${ }^{(18)}$ Concluded that simulation-based teaching consider as an Effective educational strategy that to manage obstetric emergencies on live patients in working environment which can further help in improvement of knowledge, skills as well as increase in confidence also to recognize and avoid pitfalls in managing such emergencies in real life scenario.

The investigated different aspects of knowledge in the present study encompass active managements of the third stage of labor, assessment, basic nursing measures, drug administration, evaluation\& documentation, revealed that approximately one-half of both the study and control groups had good and fair knowledge before simulation training. This finding explained by nurses as the above mentioning aspects considered the main core of nursing care for woman complaining of PPH, effectively nurses strive to learn and acquire knowledge and skills by adopting the basic knowledge needed for nursing care from the staff with whom they work most closely. Bring to light there was astonishing significant improvement in the acquisition and retention of the above-mentioned knowledge aspects were obvious among the study group after one and three months from simulation training implementation. It is worth mentioning that the study subjects' retain knowledge. Whereas simulation scenarios provide a bridge between theory and clinical practice. However, simulation is designed to utilize the acquired knowledge in interpreting the scenario arising problems, then using the key point to develop proper clinical judgment in a timely manner accordingly. In contrast, the control group point out approximately same level of knowledge throughout the study period. In this context

This finding is supported by Agha S. et al, (2015) ${ }^{(19)}$ \& Monod C. et al ,(2014) ${ }^{(20)}$ they endorse the use of simulation training as a preferred educational technique, notably they elaborated that training based on patient simulators and real patients simulation, help students to promote cognitive knowledge, technical skills, critical thinking skills and reasoning decision making and confidence during simulation sessions for clinical practice, which provide conducive learning environment and improves communication and teamwork in emergency situations.

Upon close observation, the remaining knowledge aspects reflects poor level of knowledge among both groups before training simulation implementation which includes General Management of postpartum hemorrhage, Communication(call for help), Resuscitation, Monitoring \&Investigation. Nursing management of arresting the bleeding for atonic PPH. This finding are attributed to the fact nurses accustomed to call only the doctor on duty as he is the responsible person in emergency situation approve. Unexpectedly as prevailed by nurses they consider the general management of PPH, resuscitation, monitoring and investigation, arresting the bleeding are the responsibilities of doctor also they believe that PPH is a life-threatening condition that needs qualified skillful physician to hold full responsibilities in caring for such emergency condition. Yet following simulation training they had the intense interest to redevelop their knowledge and performance skills based on evidence-based practice to improve women health as such they realized their role in prompt management of $\mathrm{PPH}$.

Overall knowledge was significantly achieved Sustainable improvement in perceived knowledge among the study group throughout the three-month period of the simulation training. Conversely, the control group showed significant low level of knowledge. This could be interpreted in the light of the study subjects' who follow simulation training approaches which considered as an effective educational strategy that captures the learners' aptitude. It also offers a creative teaching modality that allows learners to develop, refine, and apply knowledge and skills in a realistic clinical situation as they participate in interactive learning experiences designed to meet the woman needs. In this regard, Kumar N. et al ,(2016) ${ }^{(17)}$ support this results and postulated that the use of simulation is a valuable teaching modality as it allow the learner to provide accurate client assessment and make 
decisions about complex patient care management in a timely manner and participate in planning the management of adverse obstetric conditions. In this regard Karakus A. et al, (2014) ${ }^{(21)}$ corroborate that simulation-based training has emerged as a key training modality for providers of emergency obstetric care as evidence, associated with more efficient, precise nursing action through using the acquired knowledge in performing proper effective approach to emergency cases, to save patient lives and decrease the number of medical errors.

As regards the effects of simulation training program among the study group, it was obvious that it had a positive impact on improving nurses' performance. To elucidate, the level of nurses' performance regarding their role in active management of third stage of labor (AMTSL) was unsatisfactory before attending simulation training program. While post training there was a significant improvement in the study group throughout the three months since the beginning of the simulation training, compared to the majority of control group who continued to have unsatisfactory performance throughout the study period. Regrettably, this result may be due to the fact that, nurses only attend didactic session about nursing management of PPH. they did not attend any training program during the last five years however the didactic sessions alone are insufficient to improve nurses performance. Relevant with this results Ameh C. et al, $\mathbf{( 2 0 1 2}^{(\mathbf{1 8})}$ confirmed that the routine use of AMTSL reduced the incidence of $\mathrm{PPH}$, the amount of blood loss, the need for blood transfusion and additional Uterotonics, and therefore should be included in any intervention program to reduce deaths by PPH, This result is in accordance with Bogne V et.al,(2014), ${ }^{(22)}$ who reports that simulation-based teaching-learning method reflects significantly higher performance in simulation group among nurses taught about obstetrical emergencies compared to didactic teaching and those learning by means of observed practice.

Nurses' performance regarding, call for help and resuscitation were significantly improved among the study than control group after one and three months following simulation training, this results indicates that nurses never attends resuscitation training including basic life supports, restoration of blood volume and restoration of oxygen-carrying capacity for women during their reproductive life. This results is in line with Sandeep S. et al, (2014) ${ }^{(23)}$ \& Evans CL. et al, (2015) ${ }^{(24)}$ who reported that before postpartum hemorrhage simulation training, lack of knowledge and skill on management of PPH, delay to transfer the patient to the operating room and a poor communication between different professionals were identified. Post simulation using emergency care simulator, an improvement in participants resuscitation technique, enhancing emergency technical skills, improvement in knowledge, team spirit and structured communication.

It was apparent that simulation training had positive influence on nurses' performance to assess the causes of bleeding, signs of shock and accurate estimation of blood loss as using a calibrated plastic drape immediately following delivery rather than visual estimation. Foremost, nurses accurate estimation of blood loss is crucial action for early detection and prevention of severe PPH which saving mother' life. Egenberg S, et al (2015) ${ }^{(25)}$ support this finding as explained study using high fidelity PPH simulation found that midwives and obstetricians visually underestimated blood loss by $40 \%$ to $49 \%$. Ultimately visual methods were reported to have underestimated blood loss when compared with known simulated volumes, likewise, Haimee M. et $\boldsymbol{a l},(\mathbf{2 0 1 6})^{(26)}$ concluded that the estimation of blood loss after birth is very important in diagnosing, controlling and managing PPH. It is very likely that the incorrect estimation of blood loss can lead to adverse health outcome. Ultimately nurses who participated in simulation training are more skillful inaccurate estimation of blood loss and signify nursing action properly.

Arresting the bleeding of atonic PPH shows significant improvement from pre- to post-training among the study group. Virtually the only nursing measure applied to stop the bleeding is massaging the uterus and administer oxytocin according to doctor order before simulation training. Actually, they never try external or internal bimanual uterine compression or external aortic compression. Hofmeyr GJ. et al,(2012) ${ }^{(27)}$ endorse the evidence of RCT which examined the use of bimanual uterine compression and external aortic compression decrease in the amount of blood loss, furthermore, the procedure was safe for healthy subjects and benefit as a temporizing measure for the treatment of $\mathrm{PPH}$.

Concerning training on the use of non-pneumatic anti-shock garments (NASG) for reducing the blood loss of PPH. the study group demonstrate higher performance than the control group following simulation training. This results is in accordance with Miller S. et al, (2015)(28) who elaborated the NASG reverses shock by compressing the lower body vessels and decreasing the container size of the body, so circulating blood is directed mainly to the core organs of the heart, lungs, and brain. It also compresses the diameter of pelvic blood vessels, thus decreasing blood flow. The NASG was shown to significantly improve shock, decrease blood loss, reduce emergency hysterectomy for atony, and decrease maternal mortality and severe maternal morbidities associated with obstetric hemorrhage.

The overall performances of nurses were satisfactory among the majority of the study group than the control subsequent to simulation training. These results demonstrates a model for the effective and efficient use of simulation-based training which inductively permit the nurses to participate in simulated environment using relevant and realistic PPH scenarios. Consequently, gaining experience, learning and refining knowledge, skills 
and developing core competency; making reliable clinical judgment, provides opportunities for feedback, repetitive practice until proficiency is achieved. In addition, debriefing facilitated reflective thinking with the intent of transforming the simulation experience into learning. This result is in line with the study of Kumar N.et al,(2015)(18) they stated that simulation-based teaching is a better modality of teaching learning especially for obstetric emergency situation than didactic lectures. thus substantial improvement of overall skills among simulated group who performance far better in obstetric emergency situation than didactic lecture group on their first encounter with live patients

As an interactive learning method, simulation training has an apparent power in improving nurses' abilities to capture skills of the different dimension of clinical judgment among the study group. This results relies on the medium fidelity simulation was design to prepares nurses to develop clinical judgment by providing realistic patient care scenarios, yet offer an opportunity to notice, interpret, respond, and reflect in the context of clinical patient care. Subsequently, nurses critically analyze their actions, to promote technical skills, and critique their decisions, while analysis of their mistakes during debriefing. However, debriefing help nurses assess their own knowledge and facilitated reflective thinking and develop reflective practices, with the intent of transforming the simulation experience into real situation. Actually, reflection on practice is critical core for the development of clinical knowledge and improvement in clinical reasoning and facilitating in-depth understanding of theoretical knowledge used in scenarios to develop convenient clinical judgment. Moreover, acquisition of sound clinical judgment is bringing about safer, more competent care, yielding more favorable outcomes for woman health. This results are supported by Fawaz MA. et al,(2016)(29) they asserted that the intervention group exhibited higher mean score of clinical judgment with significant improvement due to exposure to high fidelity simulation than the control group. Another support by Fiona Stuedemann A. et al, (2017)(30) added that High-fidelity simulation offered a realistic learning environment for students to develop their thinking and reasoning skills and has potential to support the development of clinical judgment in nursing students

It was apparent that affirmative positive correlation was evident between nurses' knowledge, skill performance and clinical judgment among the study group throughout the study period. Lindsey PL. et al,(2013) ${ }^{(31)}$ reported that nurses integrated their knowledge and experience for making accurate clinical judgments. However accurate clinical judgment can be achieved only when nurses used clinical evidence as well as their own clinical knowledge, experience, and critical thinking skills to gain autonomy in clinical judgments. In addition, the simulation training permits opportunities to capture the essential knowledge and skills for developing reliable sound clinical judgment.

\section{Conclusion}

The results of the present study confirm unequivocal proof of the benefits of simulation training in great improvement and sustained of nurses' knowledge, performance skills, as well clinical judgments among the study group after one and three months from conducting the simulation training program regarding all items such, as active management of third stage of labor, assessment, resuscitation, arresting the bleeding, monitoring\& investigation, evaluation \&documentation. However, the control group report low level of knowledge and unsatisfactory performance skills, and low level of clinical judgment throughout the entire period of the study.

\section{Recommendations:}

1- Incorporating simulation training program in basic nursing curriculum to help professional nurse acquire the essential knowledge, performance skills, and clinical judgment for early detection and rapid effective nursing response for managing $\mathrm{PPH}$

2- Conducting periodic ongoing in service simulation training program based on approved standardized guideline for all maternity nurses about in obstetric emergencies.

3- Emergency obstetric simulation training programs to prompt nurses to play an active role in active monument of third stage of labor, resuscitation, assessment, monitoring, and arresting the bleeding.

4- Future research to explore the effect of simulation training program for maternity nurses on health outcome of mother deteriorating from $\mathrm{PPH}$.

\section{References}

[1]. Alkema L, Chou D, Hogan D, Zhang S, Moller AB, Gemmill A, et al. Global, regional, and national levels and trends in maternal mortality between 1990 and 2015, with scenario-based projections to 2030: a systematic analysis by the UN Maternal Mortality Estimation Inter-Agency Group.Lancet. 2016; 387 (10017): 462-74.

[2]. Say L, Chou D, Gemmill A, Tunçalp O, Moller AB, Daniels JD, et al. Global Causes of Maternal Death: A WHO Systematic Analysis. Lancet Global Health. 2014;2(6): 323-33.

[3]. Global Strategy for Women's, Children's and Adolescents' Health, 2016-2030.New York: United Nations; 2015.

[4]. World health organization(WHO) WHO Library Cataloguing-in-Publication Data. World health statistics 2014. Available on the WHO 
website (www.who.int)

[5]. Mousa HA, Blum J, Abou El Senoun G, Shakur H, Alfirevic Z. Treatment for primary postpartum hemorrhage. Cochrane Database of Systematic Reviews. 2014; 2. CD003249. DOI: 10.1002/14651858.CD00324

[6]. Rath W.Postpartum hemorrhage update on problems of definitions and diagnosis. Acta Obstet Gynecol Scand;2011; 90(5): 421 - 28.

[7]. Abdul-Kadir R, McLintock C, Ducloy AS. Evaluation, and management of postpartum hemorrhage: consensus from an international expert panel. Transfusion 2014; 54:56.

[8]. Tunçalp O, Souza J, Gülmezoglu M. New WHO recommendations on prevention and treatment of postpartum hemorrhage: International Journal of Gynecology and Obstetrics.2013:120;(2)186-90.

[9]. Oberg AS, Hernandez S, Palmsten K, Almqvist C, Bateman BT. Patterns of recurrence of postpartum hemorrhage in a large population-based cohort. Am J Obstet Gynecol. 2014;210:229. doi: 10.1016/j.ajog.2013.10.872.

[10]. World Health Organization. WHO Recommendations for the Prevention and Treatment of Postpartum Hemorrhage. Geneva: World Health Organization.; 2012

[11]. WHO Recommendations for Active Management of the Third Stage of Labor (AMTSL), 2012. WHO: Geneva, Switzerland

[12]. Kordi M, Fakhri F, Khadivzadeh T, Mazloum S, Akhlaghi F, Mahmoud J. Effects of Web-based Training and Educational Simulation on Midwifery Students' Self-Confidence in Postpartum Hemorrhage Management. Midwifery Reprod Health. 2015; 3(1): $262-68$.

[13]. Thompson C, Aitken B, Doran C, An agenda for clinical decision making and judgment in nursing research and education. International Journal of Nursing Studies. 2013; (50): 1720-26.

[14]. La Martina K, Smith P. Developing critical thinking skills in undergraduate nursing students: The potential for strategic management simulations. Journal of Nursing Education and Practice. 2014; 4(9):155-62.

[15]. Lasater K, Clinical Judgment Development: Using Simulation to Create an Assessment Rubric. Journal of Nursing Education.2007;46(11): 496-503.

[16]. Ayres C, Deering, D. Siassakos. Sustaining simulation training programs-experience from maternity care. Br. J. Obstet. Gynecol., 118 (2011), pp. 22-26

[17]. Kumar N, Kant N, Samar S. Role of Simulation-based teaching in Management of Postpartum Hemorrhage amongst Postgraduate Students of Department of Obstetrics and Gynecology: A Prospective Study future of medical education journal.2016;(1):31-35.

[18]. Ameh C, Adegoke A, Hofman J . The impact of emergency obstetric care training in Somaliland, Somalia. Int Gynaecol Obstet. 2012; 117: $283-87$.

[19]. Agha S, Alhamrani A, Khan M. Satisfaction of medical students with simulation-based learning. Saudi Med J. 2015; 36(6): 731-36.

[20]. Monod C, Voekt A, Gisin M, Gisin S, Irene M. Optimization of competency in obstetrical emergencies: a role for simulation training. Arch Gynecol Obstet. (2014) 289:33-738DOI 10.1007/s00404-013-3111-6.

[21]. Karakus A, Şenyer N. The preparedness level of final year medical students for an adequate medical approach to emergency cases: computer-based medical education in emergency medicine. International Journal of Emergency Medicine December 2014;7:3 doi: $10.1186 / 1865-1380-7-3$.

[22]. Bogne V., Kirkpatrick C., Englert Y. Simulation training in the management of obstetric emergencies. A review of the literature. Revue Medicale de Bruxelles. 2014;35(6):491-98.

[23]. Sandeep S, Indu L. Simulation training in the management of obstetric emergencies. A review of the literature. Rev Med Brux. 2014 Nov-Dec;35(6):491-8.

[24]. Evans CL, Johnson P, Bazant E, Bhatnagar N, Zgambo J, Khamis AR. Competency-based training "Helping Mothers Survive: Bleeding after Birth" for providers from central and remote facilities in three countries. Acta Obstet Gynecol Scand. 2015; 94(3): 31623.

[25]. Egenberg S, Oian P, Bru LE, Sautter M, Kristoffersen G, Eggebo TM. Can inter-professional simulation training influence the frequency of blood transfusions after birth?. Acta Obstet Gynecol Scand .2015; 94: 316-23.

[26]. Haimee M, Souza M, Khanum S, Naz N. Raduenz A. The Practice of Nursing in the Prevention and Control of Postpartum Hemorrhage: An Integrative Review. American Journal of Nursing Science. 2016;5(1):8-15.

[27]. Hofmeyr GJ, Abdel-Aleem H, Abdel-Aleem MA.Uterine massage for preventing postpartum hemorrhage.Cochrane Database of Systematic Reviews.2013;(7). 1-40. CD006431 DOI: 10.1002/14651858.CD006431.

[28]. Miller S, Belizán J. A promising device to save maternal lives associated with obstetric hemorrhage: the non-pneumatic anti-shock garment (NASG).Journal of Reproductive Health, 2015; 12:26. DOI 10.1186/s12978-015-0019-6.

[29]. Fawaz MA, -Mansour AM. Impact of high-fidelity simulation on the development of clinical judgment and motivation among Lebanese nursing students. Nurse Educ Today. 2016 ;46:36-42.

[30]. Stuedemann A, Thomas K. Examining the Relationship Between Clinical Judgment and Nursing Actions in Prelicensure Students.J Nurse Educator.2017;42( 1): 47-50.

[31]. Lindsey PL, Jenkins S. Nursing students' clinical judgment regarding rapid response: the influence of a clinical simulation education intervention. Nurs Forum. 2013;48(1):61-7

Table (I): Number and percent distribution of the study participant according to their professional character

\begin{tabular}{|c|c|c|c|c|c|c|}
\hline \multirow[t]{2}{*}{$\mathbf{P}$} & \multirow[t]{2}{*}{ Test of sig. } & \multicolumn{2}{|c|}{ Control group $(\mathrm{n}=50)$} & \multicolumn{2}{|c|}{ Study group $(\mathbf{n}=\mathbf{5 0})$} & \multirow[t]{2}{*}{ Socio-demographic characteristics } \\
\hline & & $\%$ & No & $\%$ & No & \\
\hline \multirow[t]{2}{*}{$\mathrm{p}=0.980$} & $\mathrm{HM}=0.025$ & $\begin{array}{l}30 \\
50 \\
20 \\
\end{array}$ & $\begin{array}{l}15 \\
25 \\
10 \\
\end{array}$ & $\begin{array}{l}24 \\
54 \\
22\end{array}$ & $\begin{array}{l}12 \\
27 \\
11 \\
\end{array}$ & $\begin{array}{l}\text { Age (year): } \\
<30 \\
30-40 \\
>40-59 \\
\end{array}$ \\
\hline & & \multicolumn{2}{|c|}{$34.72 \pm 4.79$} & \multicolumn{2}{|c|}{$36.97+9.486$} & Mean \pm SD \\
\hline $\mathrm{p}=0.345$ & $\mathrm{HM}=0.700$ & $\begin{array}{c}76 \\
18 \\
6 \\
\end{array}$ & $\begin{array}{c}38 \\
9 \\
3 \\
\end{array}$ & $\begin{array}{c}80 \\
14 \\
6 \\
\end{array}$ & $\begin{array}{c}40 \\
7 \\
3 \\
\end{array}$ & $\begin{array}{l}\text { The level of education: } \\
\text { Diploma in nursing } \\
\text { Bachelor } \\
\text { Master }\end{array}$ \\
\hline $\mathrm{p}=0.396$ & $\mathrm{HM}=0.050$ & $\begin{array}{l}90 \\
10 \\
\end{array}$ & $\begin{array}{c}45 \\
5 \\
\end{array}$ & $\begin{array}{l}88 \\
12 \\
\end{array}$ & $\begin{array}{c}44 \\
6 \\
\end{array}$ & $\begin{array}{l}\text { Employment Position: } \\
\text { Nurse } \\
\text { Supervisor }\end{array}$ \\
\hline $\mathrm{p}=0.330$ & $\mathrm{HM}=0.418$ & 40 & 20 & 46 & 23 & $\begin{array}{l}\text { Years of experience in nursing: } \\
<10\end{array}$ \\
\hline
\end{tabular}


Effect of a Medium Fidelity Simulation Based Training on Nurses' Knowledge, Performance and ..

\begin{tabular}{|l|l|l|l|l|l|l|}
\hline & & 60 & 30 & 54 & 27 & $>10-$ \\
\hline $\mathrm{p}=0.259$ & $\mathrm{HM}=1.392$ & & & & & Attending Emergency Obstetrics Training \\
& & 68 & 34 & 62 & 31 & Yes \\
& & 32 & 16 & 38 & 19 & No \\
\hline $\mathrm{p}=0.160$ & $\mathrm{HM}=1.433$ & 44 & 22 & 52 & 26 & $1-2$ \\
& & 56 & 27 & 48 & 24 & $<2$ \\
\hline
\end{tabular}

Test of significance MH: Marginal Homogeneity test

*significant at $\mathbf{P} \square 0.05$

Table (2): Percent distribution of nurses' knowledge regarding primary postpartum hemorrhage before and after simulation training program implementation.

\begin{tabular}{|c|c|c|c|c|c|c|c|c|c|}
\hline \multirow{2}{*}{$\begin{array}{c}\text { Test of } \\
\text { significance }\end{array}$} & \multicolumn{2}{|c|}{ After 3 months } & \multirow{2}{*}{$\begin{array}{c}\text { Test of } \\
\text { significance }\end{array}$} & \multicolumn{2}{|c|}{ After one month } & \multirow{2}{*}{$\begin{array}{c}\text { Test of } \\
\text { significance }\end{array}$} & \multicolumn{2}{|c|}{ Pre-program } & \multirow[t]{2}{*}{ Nurses knowledge } \\
\hline & control & study & & control & study & & control & study & \\
\hline $\begin{array}{l}\mathrm{MH}=5.807 \\
\mathrm{P}<0.0001 *\end{array}$ & $\begin{array}{l}14 \\
50 \\
36\end{array}$ & $\begin{array}{c}82 \\
18 \\
0\end{array}$ & $\begin{array}{l}\mathrm{HM}=5.117 \\
\mathrm{P}<0.0001 *\end{array}$ & $\begin{array}{l}16 \\
54 \\
30\end{array}$ & $\begin{array}{c}86 \\
14 \\
0\end{array}$ & $\begin{array}{c}\mathrm{HM}=0.667 \\
\mathrm{P}=0.505\end{array}$ & $\begin{array}{l}14 \\
56 \\
30\end{array}$ & $\begin{array}{l}16 \\
48 \\
36\end{array}$ & $\begin{array}{l}\text { General knowledge } \\
\text { Good } \\
\text { Fair } \\
\text { poor }\end{array}$ \\
\hline $\begin{array}{l}\mathrm{MH}=5.919 \\
\mathrm{P}<0.0001 *\end{array}$ & $\begin{array}{l}14 \\
38 \\
48\end{array}$ & $\begin{array}{c}82 \\
18 \\
0\end{array}$ & $\begin{array}{l}\mathrm{HM}=4.341 \\
\mathrm{P}<0.0001 *\end{array}$ & $\begin{array}{l}16 \\
40 \\
44\end{array}$ & $\begin{array}{c}84 \\
16 \\
0\end{array}$ & $\begin{array}{l}\mathrm{HM}=1.0 \\
\mathrm{P}=0.317\end{array}$ & $\begin{array}{l}14 \\
38 \\
48\end{array}$ & $\begin{array}{l}12 \\
34 \\
54\end{array}$ & $\begin{array}{l}\text { Active managements of the third } \\
\text { stage of labor } \\
\text { Good } \\
\text { Fair } \\
\text { poor }\end{array}$ \\
\hline $\begin{array}{l}\mathrm{MH}=5.616 \\
\mathrm{P}<0.0001 *\end{array}$ & $\begin{array}{c}4 \\
10 \\
86\end{array}$ & $\begin{array}{c}86 \\
34 \\
9\end{array}$ & $\begin{array}{l}\mathrm{HM}=5.078 \\
\mathrm{P}<0.0001 *\end{array}$ & $\begin{array}{c}8 \\
12 \\
80\end{array}$ & $\begin{array}{c}92 \\
8 \\
0\end{array}$ & $\begin{array}{l}\mathrm{HM}=1.4 \\
\mathrm{P}=0.162\end{array}$ & $\begin{array}{c}4 \\
18 \\
78\end{array}$ & $\begin{array}{c}6 \\
12 \\
82\end{array}$ & $\begin{array}{l}\text { General Management of PPH } \\
\text { Communication(call for help) } \\
\text { Good } \\
\text { Fair } \\
\text { poor }\end{array}$ \\
\hline $\begin{array}{l}\mathrm{MH}=5.688 \\
\mathrm{P}<0.0001^{*}\end{array}$ & $\begin{array}{c}4 \\
16 \\
80\end{array}$ & $\begin{array}{c}92 \\
8 \\
0\end{array}$ & $\begin{array}{l}\mathrm{HM}=3.939 \\
\mathrm{P}<0.0001 *\end{array}$ & $\begin{array}{c}4 \\
14 \\
82\end{array}$ & $\begin{array}{c}94 \\
6 \\
0\end{array}$ & $\begin{array}{c}H M=0.539 \\
P=0.59\end{array}$ & $\begin{array}{c}6 \\
16 \\
78\end{array}$ & $\begin{array}{c}4 \\
12 \\
84\end{array}$ & $\begin{array}{l}\text { Resuscitation } \\
\text { Good } \\
\text { Fair } \\
\text { poor }\end{array}$ \\
\hline $\begin{array}{l}\mathrm{MH}=5.674 \\
\mathrm{P}<0.0001^{*}\end{array}$ & $\begin{array}{l}10 \\
50 \\
40\end{array}$ & $\begin{array}{c}82 \\
18 \\
0\end{array}$ & $\begin{array}{l}\mathrm{HM}=4.264 \\
\mathrm{P}<0.0001 *\end{array}$ & $\begin{array}{c}6 \\
50 \\
44\end{array}$ & $\begin{array}{c}86 \\
14 \\
0\end{array}$ & $\begin{array}{c}H M=0.567 \\
P=0.905\end{array}$ & $\begin{array}{c}4 \\
54 \\
42\end{array}$ & $\begin{array}{c}8 \\
58 \\
34\end{array}$ & $\begin{array}{l}\text { Assessment } \\
\text { Good } \\
\text { Fair } \\
\text { Poor }\end{array}$ \\
\hline $\begin{array}{l}\mathrm{MH}=5.774 \\
\mathrm{P}<0.0001 *\end{array}$ & $\begin{array}{c}26 \\
66 \\
8\end{array}$ & $\begin{array}{c}82 \\
18 \\
0\end{array}$ & $\begin{array}{l}\mathrm{HM}=4.111 \\
\mathrm{P}<0.0001 *\end{array}$ & $\begin{array}{c}26 \\
70 \\
4\end{array}$ & $\begin{array}{c}88 \\
12 \\
0\end{array}$ & $\begin{array}{c}H M=1.043 \\
P=0.297\end{array}$ & $\begin{array}{c}28 \\
68 \\
4\end{array}$ & $\begin{array}{c}32 \\
62 \\
6\end{array}$ & $\begin{array}{l}\text { Basic nursing measures } \\
\text { Good } \\
\text { Fair } \\
\text { poor }\end{array}$ \\
\hline $\begin{array}{l}\mathrm{MH}=5.919 \\
\mathrm{P}<0.0001 *\end{array}$ & $\begin{array}{l}10 \\
34 \\
56\end{array}$ & $\begin{array}{c}80 \\
20 \\
0\end{array}$ & $\begin{array}{l}\mathrm{HM}=5.919 \\
\mathrm{P}<0.0001 *\end{array}$ & $\begin{array}{l}10 \\
36 \\
44\end{array}$ & $\begin{array}{c}86 \\
14 \\
0\end{array}$ & $\begin{array}{c}\mathrm{HM}=1.291 \\
\mathrm{P}=0.197\end{array}$ & $\begin{array}{l}12 \\
32 \\
56\end{array}$ & $\begin{array}{l}14 \\
34 \\
52\end{array}$ & $\begin{array}{l}\text { Monitoring \&Investigation } \\
\text { Good } \\
\text { Fair } \\
\text { poor }\end{array}$ \\
\hline $\begin{array}{l}\mathrm{MH}=5.687 \\
\mathrm{P}<0.0001 *\end{array}$ & $\begin{array}{c}0 \\
10 \\
90\end{array}$ & $\begin{array}{c}88 \\
12 \\
0\end{array}$ & $\begin{array}{l}\mathrm{HM}=5.899 \\
\mathrm{P}<0.0001^{*}\end{array}$ & $\begin{array}{c}0 \\
14 \\
86\end{array}$ & $\begin{array}{c}92 \\
8 \\
0\end{array}$ & $\begin{array}{c}H M=0.392 \\
P=0.695\end{array}$ & $\begin{array}{c}0 \\
8 \\
92\end{array}$ & $\begin{array}{c}0 \\
12 \\
88\end{array}$ & $\begin{array}{l}\text { Arresting the bleeding } \\
\text { Good } \\
\text { Fair } \\
\text { poor }\end{array}$ \\
\hline $\begin{array}{l}\mathrm{MH}=5.715 \\
\mathrm{P}<0.0001 *\end{array}$ & $\begin{array}{c}26 \\
58 \\
6\end{array}$ & $\begin{array}{c}44 \\
56 \\
0\end{array}$ & $\begin{array}{l}\mathrm{HM}=5.346 \\
\mathrm{P}<0.0001 *\end{array}$ & $\begin{array}{l}30 \\
58 \\
12\end{array}$ & $\begin{array}{c}46 \\
54 \\
0\end{array}$ & $\begin{array}{c}\mathrm{HM}=1.622 \\
\mathrm{P}=0.105\end{array}$ & $\begin{array}{l}28 \\
60 \\
12\end{array}$ & $\begin{array}{l}24 \\
62 \\
14\end{array}$ & $\begin{array}{l}\text { Drug administration } \\
\text { Good } \\
\text { Fair } \\
\text { poor }\end{array}$ \\
\hline $\begin{array}{c}\mathrm{MH}=5.096 \\
\mathrm{P}<0.0001\end{array}$ & $\begin{array}{l}24 \\
40 \\
36\end{array}$ & $\begin{array}{c}74 \\
26 \\
0\end{array}$ & $\begin{array}{l}\mathrm{MH}=4.469 \\
\mathrm{P}<0.0001 *\end{array}$ & $\begin{array}{l}26 \\
44 \\
30\end{array}$ & $\begin{array}{c}78 \\
22 \\
0\end{array}$ & $\begin{array}{c}H M=0.864 \\
P=0932\end{array}$ & $\begin{array}{l}28 \\
40 \\
32\end{array}$ & $\begin{array}{l}34 \\
36 \\
30\end{array}$ & $\begin{array}{l}\text { Evaluation\& Documentation } \\
\text { Good } \\
\text { Fair } \\
\text { poor }\end{array}$ \\
\hline
\end{tabular}

Test of significance MH: Marginal Homogeneity test

*significant at $\mathrm{P} \leq 0.05$

Figure (1) Total score of nurses knowledge before and after simulation training 
Effect of a Medium Fidelity Simulation Based Training on Nurses' Knowledge, Performance and ..

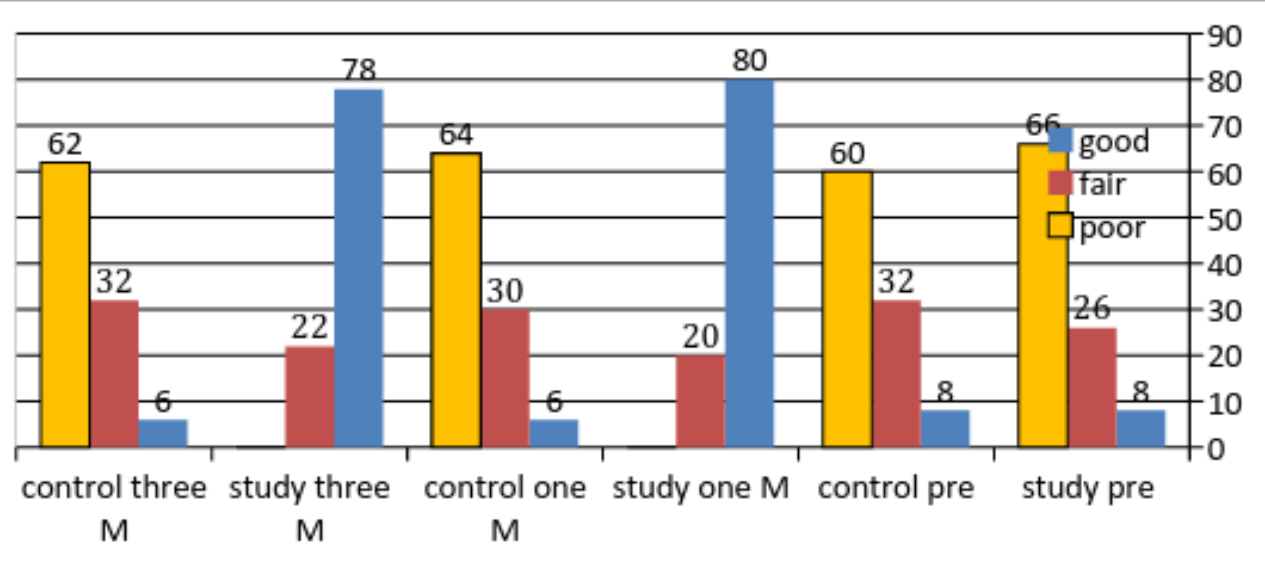

Table (3) Percent distribution of the study participant according to their performance skills of managing atonic postpartum hemorrhage before and after simulation training program implementation.

\begin{tabular}{|c|c|c|c|c|c|c|c|c|c|}
\hline \multirow[t]{2}{*}{ McNemar test } & \multicolumn{2}{|c|}{ After 3 months } & \multirow{2}{*}{$\begin{array}{l}\text { McNear } \\
\text { test }\end{array}$} & \multicolumn{2}{|c|}{ After one month } & \multirow{2}{*}{$\begin{array}{l}\text { McNemr } \\
\text { test }\end{array}$} & \multicolumn{2}{|c|}{ Pre-program } & \multirow{2}{*}{$\begin{array}{l}\text { Nursing performance skills of primary } \\
\text { PPH }\end{array}$} \\
\hline & control & study & & control & study & & control & study & \\
\hline $\mathrm{MNP}<0.000^{*}$ & $\begin{array}{l}20 \\
80\end{array}$ & $\begin{array}{l}84 \\
16\end{array}$ & $\begin{array}{l}{ }^{\mathrm{MN}} \mathrm{P}<0.000 \\
1^{*}\end{array}$ & $\begin{array}{l}20 \\
80\end{array}$ & $\begin{array}{l}88 \\
12\end{array}$ & ${ }^{\mathrm{MN}} \mathrm{P}=0.46$ & $\begin{array}{l}22 \\
78\end{array}$ & $\begin{array}{l}18 \\
82\end{array}$ & $\begin{array}{l}\text { Active managements of the third stage } \\
\text { of labor } \\
\text { Satisfactory } \\
\text { Unsatisfactory }\end{array}$ \\
\hline $\mathrm{MNP}<0.000^{*}$ & $\begin{array}{l}12 \\
88\end{array}$ & $\begin{array}{l}76 \\
24\end{array}$ & $\begin{array}{c}{ }^{\mathrm{MN}} \mathrm{P}<0.000 \\
1^{*}\end{array}$ & $\begin{array}{l}10 \\
90\end{array}$ & $\begin{array}{l}82 \\
18\end{array}$ & & $\begin{array}{l}20 \\
80\end{array}$ & $\begin{array}{l}16 \\
84\end{array}$ & $\begin{array}{l}\text { 1-Communication } \\
\text { Satisfactory } \\
\text { Unsatisfactory }\end{array}$ \\
\hline $\mathrm{MNP}<0.000^{*}$ & $\begin{array}{l}18 \\
82\end{array}$ & $\begin{array}{c}92 \\
8\end{array}$ & $\begin{array}{c}{ }^{\mathrm{MN}} \mathrm{P}<0.000 \\
1 * *\end{array}$ & $\begin{array}{l}18 \\
82\end{array}$ & $\begin{array}{c}94 \\
6\end{array}$ & ${ }^{\mathrm{MN}} \mathrm{P}=0.115$ & $\begin{array}{l}28 \\
78\end{array}$ & $\begin{array}{l}20 \\
80\end{array}$ & $\begin{array}{l}\text { 2-Resuscitation } \\
\text { Satisfactory } \\
\text { Unsatisfactory }\end{array}$ \\
\hline $\mathrm{MNP}<0.000^{*}$ & $\begin{array}{l}16 \\
84\end{array}$ & $\begin{array}{l}86 \\
14\end{array}$ & $\begin{array}{l}{ }^{\mathrm{MN}} \mathrm{P}<0.000 \\
1^{*}\end{array}$ & $\begin{array}{l}22 \\
78\end{array}$ & $\begin{array}{l}88 \\
12\end{array}$ & ${ }^{\mathrm{MN}} \mathrm{P}=0.125$ & $\begin{array}{l}18 \\
82\end{array}$ & $\begin{array}{l}22 \\
78\end{array}$ & $\begin{array}{l}\text { 3-Assessment } \\
\text { Satisfactory } \\
\text { Unsatisfactory }\end{array}$ \\
\hline $\mathrm{MNP}<0.000^{*}$ & $\begin{array}{c}0 \\
100\end{array}$ & $\begin{array}{l}90 \\
10\end{array}$ & $\begin{array}{l}{ }^{\mathrm{MN}} \mathrm{P}<0.000 \\
1 *\end{array}$ & & $\begin{array}{c}92 \\
80 \\
100\end{array}$ & $\begin{array}{c}\mathrm{MNP}= \\
0.105\end{array}$ & $\begin{array}{c}0 \\
100\end{array}$ & $\begin{array}{c}0 \\
100\end{array}$ & $\begin{array}{l}\text { 4-Arresting the bleeding } \\
\text { Satisfactory } \\
\text { Unsatisfactory }\end{array}$ \\
\hline MNP $<0.000^{*}$ & $\begin{array}{l}22 \\
78\end{array}$ & $\begin{array}{l}88 \\
12\end{array}$ & $\begin{array}{l}{ }^{\mathrm{MN}} \mathrm{P}<0.000 \\
1^{*}\end{array}$ & $\begin{array}{l}26 \\
74\end{array}$ & $\begin{array}{l}88 \\
12\end{array}$ & ${ }^{\mathrm{MN}} \mathrm{P}=0.375$ & $\begin{array}{l}32 \\
68\end{array}$ & $\begin{array}{l}30 \\
70\end{array}$ & $\begin{array}{l}\text { 5-Basic nursing measures } \\
\text { Satisfactory } \\
\text { Unsatisfactory }\end{array}$ \\
\hline MNP $<0.000^{*}$ & $\begin{array}{l}10 \\
90\end{array}$ & $\begin{array}{l}82 \\
18\end{array}$ & $\begin{array}{c}{ }^{\mathrm{MN}} \mathrm{P}<0.000 \\
1 *\end{array}$ & $\begin{array}{l}14 \\
86\end{array}$ & $\begin{array}{l}86 \\
14\end{array}$ & ${ }^{\mathrm{MN}} \mathrm{P}=0.375$ & $\begin{array}{l}12 \\
88\end{array}$ & $\begin{array}{c}8 \\
92\end{array}$ & $\begin{array}{l}\text { 6Monitoring\&Investigation } \\
\text { Satisfactory } \\
\text { Unsatisfactory }\end{array}$ \\
\hline MNP $<0.000^{*}$ & $\begin{array}{l}30 \\
70\end{array}$ & $\begin{array}{l}86 \\
14\end{array}$ & $\begin{array}{c}{ }^{\mathrm{MN}} \mathrm{P}<0.000 \\
1 *\end{array}$ & $\begin{array}{l}28 \\
72\end{array}$ & $\begin{array}{l}88 \\
12\end{array}$ & ${ }^{\mathrm{MN}} \mathrm{P}=0.317$ & $\begin{array}{l}26 \\
74\end{array}$ & $\begin{array}{l}24 \\
62\end{array}$ & $\begin{array}{l}\text { 7-Drug Administration } \\
\text { Satisfactory } \\
\text { Unsatisfactory }\end{array}$ \\
\hline MNP $<0.000^{*}$ & $\begin{array}{l}24 \\
76\end{array}$ & $\begin{array}{l}74 \\
26\end{array}$ & $\begin{array}{c}{ }^{\mathrm{MN}} \mathrm{P}<0.000 \\
1 *\end{array}$ & $\begin{array}{l}28 \\
76\end{array}$ & $\begin{array}{l}78 \\
22\end{array}$ & ${ }^{\mathrm{MN}} \mathrm{P}=0.415$ & $\begin{array}{l}32 \\
68\end{array}$ & $\begin{array}{l}38 \\
62\end{array}$ & $\begin{array}{l}\text { 8-Evaluation\&Documentation } \\
\text { Satisfactory } \\
\text { Unsatisfactory }\end{array}$ \\
\hline
\end{tabular}

P: McNemar test

*significant at $\mathbf{P} \leq \mathbf{0 . 0 5}$ 
Effect of a Medium Fidelity Simulation Based Training on Nurses' Knowledge, Performance and ..

Figure (2): Total score of nurses' performance skills before and after simulation training program.

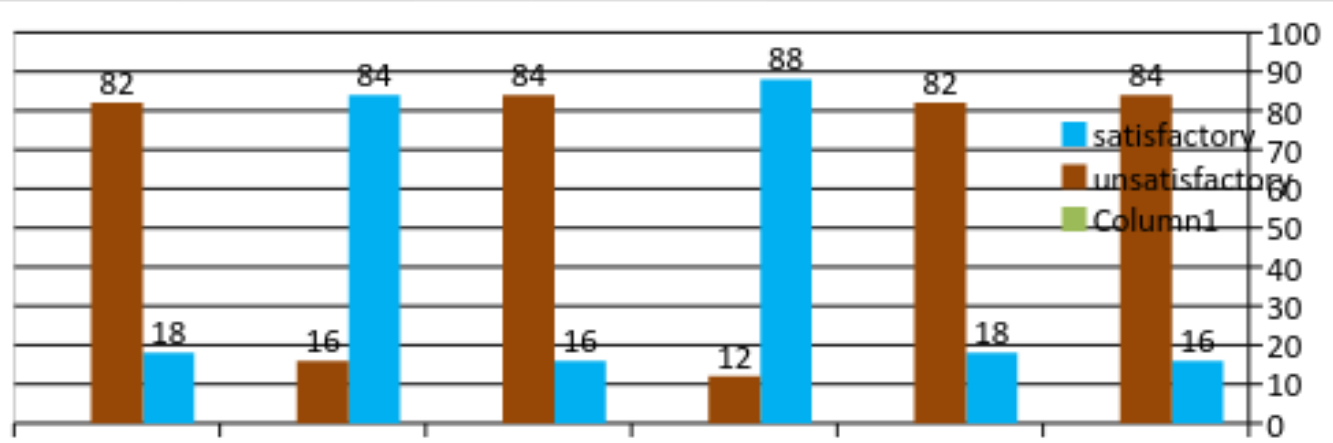

control three study three $\mathrm{M}$ control one $\mathrm{M}$ study one $\mathrm{M}$ control pre study pre

$\mathrm{M}$

Table (4) distribution of mean score of the study participants' clinical judgment before and after simulation

\begin{tabular}{|c|c|c|c|c|c|c|c|c|c|}
\hline \multirow[t]{2}{*}{ T-test } & \multicolumn{2}{|c|}{ After three month } & \multirow[t]{2}{*}{ T-test } & \multicolumn{2}{|c|}{ After one month } & \multirow[t]{2}{*}{ T-test } & \multicolumn{2}{|c|}{ Pre-program } & \multirow[t]{2}{*}{ Clinical Judgment } \\
\hline & control & study & & control & study & & control & study & \\
\hline $\begin{array}{l}\mathrm{t}=6.004 \\
\mathrm{P}=.000\end{array}$ & $5.35 \pm 1.37$ & $\begin{array}{l}8.07 \pm \\
1.18\end{array}$ & $\begin{array}{l}\mathrm{t}=5.07 \\
\mathrm{P}=.000\end{array}$ & $5.58 \pm 0.79$ & $8.88 \pm 1.97$ & $\begin{array}{l}\mathrm{t}=-1.509 \\
\mathrm{P}=.134\end{array}$ & $5.63 \pm 1.67$ & $5.46 \pm 1.52$ & Noticing \\
\hline $\begin{array}{l}\mathrm{t}=10.672 \\
\mathrm{P}=.000\end{array}$ & $3.63 \pm 1.08$ & $\begin{array}{l}6.58 \pm \\
0.36\end{array}$ & $\begin{array}{l}\mathrm{t}=5.71 \\
\mathrm{P}=.000\end{array}$ & $3.78 \pm 0.89$ & $7.82 \pm 0.96$ & $\begin{array}{l}\mathrm{t}=0.720 \\
\mathrm{P}=.473\end{array}$ & $3.78 \pm 0.84$ & $3.83 \pm 0.78$ & Interpreting \\
\hline $\begin{array}{l}\mathrm{t}=9.479 \\
\mathrm{P}=.000\end{array}$ & $6.92 \pm 1.69$ & $\begin{array}{l}10.35 \pm \\
1.27\end{array}$ & $\begin{array}{l}\mathrm{t}=7.79 \\
\mathrm{P}=.000\end{array}$ & $6.79 \pm 1.34$ & $10.13 \pm 1.58$ & $\begin{array}{l}\mathrm{t}=-2.806 \\
\mathrm{P}=.336\end{array}$ & $6.76 \pm 1.28$ & $6.54 \pm 1.47$ & Responding \\
\hline $\begin{array}{l}\mathrm{t}=6.007 \\
\mathrm{P}=.000\end{array}$ & $3.78 \pm 1.26$ & $\begin{array}{l}6.71 \pm \\
0.69\end{array}$ & $\begin{array}{l}\mathrm{t}=4.390 \\
\mathrm{P}=.000\end{array}$ & $3.83 \pm 0.75$ & $6.26 \pm 1.23$ & $\begin{array}{l}\mathrm{t}=1.129 \\
\mathrm{P}=.262\end{array}$ & $3.56 \pm 0.94$ & $3.38 \pm 0.89$ & Reflecting \\
\hline $\begin{array}{l}\mathrm{t}=10.948 \\
\mathrm{P}=.000\end{array}$ & $18.77 \pm 2.71$ & $\begin{array}{l}31.65 \pm \\
3.1\end{array}$ & $\begin{array}{l}\mathrm{t}=7.05 \\
\mathrm{P}=.000\end{array}$ & $19.45 \pm 2.42$ & $33.87 \pm 4.47$ & $\begin{array}{l}\mathrm{t}=-1.046 \\
\mathrm{P}=.298\end{array}$ & $\begin{array}{l}19.96 \pm \\
3.89\end{array}$ & $19.27 \pm 4.72$ & Total score \\
\hline
\end{tabular}

Table (5) Correlation between the study and control participants 'clinical judgment with their knowledge \& performance skills.

\begin{tabular}{|c|c|c|c|c|c|c|c|c|c|c|c|c|}
\hline \multicolumn{6}{|c|}{ Clinical judgment ( control group) } & \multicolumn{6}{|c|}{ Clinical judgment ( study group) } & \multirow{3}{*}{$\begin{array}{l}\text { Total knowledge } \\
\text { \&skills score }\end{array}$} \\
\hline \multicolumn{2}{|c|}{ after 3 months } & \multicolumn{2}{|c|}{ after one month } & \multicolumn{2}{|c|}{ pre } & \multicolumn{2}{|c|}{ after 3 months } & \multicolumn{2}{|c|}{ after one month } & \multicolumn{2}{|c|}{ pre } & \\
\hline $\mathbf{p}$ & $\mathbf{r}$ & $\mathbf{p}$ & $\mathbf{r}$ & $\mathbf{p}$ & $\mathbf{r}$ & $\mathbf{p}$ & $\mathbf{r}$ & $\mathbf{p}$ & $\mathbf{r}$ & $\mathbf{p}$ & $\mathbf{r}$ & \\
\hline 0.683 & -0.046 & 0.346 & -0.322 & $0.302-$ & $0.176-$ & $<0.001$ & $0.756^{*}$ & $<0.001$ & $0.587^{*}$ & 0.293 & -0.119 & knowledge \\
\hline 0.758 & -0.035 & 0.153 & -0.214 & $0.461-$ & -0.023 & $<0.001$ & $0.714^{*}$ & $<0.001$ & $0.616^{*}$ & 0.253 & -0.148 & skills \\
\hline
\end{tabular}

r: Pearson coefficient *: Statistically significant at $\mathrm{p} \leq 0.05$ 